\title{
Effect of 3D parameters on Antifungal Activities of Some Heterocyclic Compounds
}

\author{
Anita $\mathrm{K}^{*}$,Vijay K. Agrawal ${ }^{2}$, Bashirulla Shaik ${ }^{2}$, Shweta Sharma ${ }^{3}$ \\ ${ }^{1,3}$ Dept. of Chemistry, Career College, Bhopal, Madhya Pradesh, India \\ ${ }^{2}$ Dept. of Applied Science, National Institute of Technical Teachers Training and Research, Shamla Hills, \\ Bhopal-462002, Madhya Pradesh, India
}

\begin{abstract}
Quantitative Structure Activity Relationships (QSAR) of some heterocyclic compounds was studied using some $3 D$ parameters. The QSAR models indicated that Dipole Y, Dipole mag., Y length and some indicator parameters are very effective in describing the antifungal activities of these compounds against Candida albicans in the training and external test set. The multiple regression analysis have produced well predictive statistically significant and cross validated QSAR models which help to explore some expectedly potent compounds.
\end{abstract}

Key words: QSAR, Dipole Y, Dipole mag, Y length, indicator parameters, cross validation

\section{Introduction}

Despite of tremendous progress on medicinal chemistry, infectious diseases have dramatically increased and become a major threat to human health. Infections caused by fungal species are common in immuno-compromised patients and carry significant treatment cost and mortality [1]. Antibacterial resistance is a growing problem which makes the discovery of potent antibiotics with activity against resistant strains very essential [2].

Derivatives of benzoxazoles, benzimidazoles and oxazolopyrimidines and benzothiazoles have been found to possess inhibitory properties against Candida albicans. We know that Candida causes infections which are yeast like fungus and in medical terms commonly known as candidiasis [3].Studies reveal that most fungi are completely resistant to antimicrobial agents; therefore new agents are required which possess inhibitory effect and must be relatively less toxic. The above mentioned compounds and their derivatives are known for their antifungal activities and also they have less toxicity.

QSAR is one of the important tools of drug designing used in medicinal chemistry. QSAR models are mathematical equations which correlates chemical structure to physico-chemical and biological properties. The desired relationship between molecular descriptors and activity is used to estimate the property of other molecules or to calculate the important parameters affecting the biological activity [4].

Antifungal activities of various compounds have been modeled in recent past by many workers. They have showed that Topological descriptors can be used for estimating antifungal activities of the compounds. In the present study we have selected 68 such compounds. During our study we found that Dipole mag., Dipole Y, $\mathrm{Y}$ length and indicator parameters are highly co-related with the antifungal activities of these compounds.

The magnitude of dipole moment has been used as a descriptor in QSAR studies. The magnitudes of one or more of the vector components along $\mathrm{X}, \mathrm{Y}$, and $\mathrm{Z}$ axis have been found to be a good descriptor in QSAR studies. Dipole moment can influence electrostatic interactions of biological macromolecules. Electric dipoles aligned themselves parallel to external electric field but in the opposite direction resulting in decrease of the magnitude of the field. Thus the magnitude of dipole moment could be a measure of the ability of a molecule to diminish the electric field across lipid membranes which in turn will influence membrane transport.

In this study we have also used few indicator parameters $\mathrm{IP}_{1}, \mathrm{IP}_{2}, \mathrm{IP}_{3}$ which are related to substituent $\mathrm{X}$, $\mathrm{R}_{1}$, and $\mathrm{Z}$. These parameters show the significance of a particular group or substituent in the given series of drug. They account for the increase or decrease of a given pharmacological activity at any specific site in the drug molecule [5].The general structure of antifungal compounds which are active against Candida albicans is shown below:

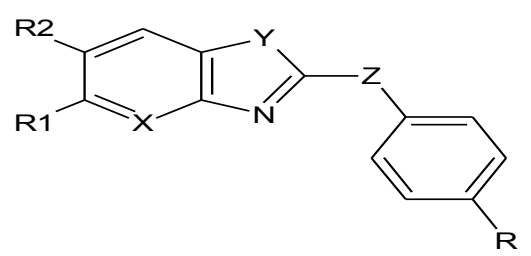

Fig.1. General Structure of antifungal compound used in the present study 


\section{Experimental}

Quantitative Structure Activity Relationship (QSAR) modeling establishes a quantitative correlation between chemical structure and biological activity [6]. In the present study we have considered 68 compounds having antifungal activities against Candida albicans which have been represented in terms of $\log 1 / \mathrm{C}$ values, where $C$ is the molar concentration of a compound and $\log 1 / C$ is the dependent variable that defines the biological parameter for QSAR equations. Activities of these compounds have been taken from literature [7]. The structural details of compounds used in the present study are given in Table 1.

In order to obtain a validated QSAR model for meaningful predictions, the data set should be divided into training and test sets. The dataset is divided into a training set and a test set molecules on the basis of chemical and biological diversity using the random selection method. Accelry's Discovery Studio software has been used for calculation of the descriptors. These calculated descriptorsinclude: the energy value of LUMO (Lowest Unoccupied Molecular Orbital), Dipole mag., Dipole Y, Jurs FNSA 3, PMI X, Shadow Y length, Shadow YZ. From the descriptors calculated useful descriptors were selected by variable selection procedure of multiple regression analysis using NCSS software [8]. A relationship between independent and dependent variables (calculated parameters and biological activities) were determined statistically using regression analysis. Linear regression is achieved by fitting a best-fit straight line to the data using the least square method. The quality of fit for a regression equation was assessed relative to its correlation coefficient and standard deviation. The $\mathrm{F}$ value represents the level of statistical significance of the regression. Quality of selected models was further ascertained to select the best model from cross-validated squared correlation coefficient $\left(\mathrm{r}^{2}\right)$.

The model validation is done to test the stability and predictive ability of the QSAR models. The developed models were validated by internal validation using leave-one-out method [9].For calculating $\mathrm{r}^{2}$ each molecule in the training set was eliminated once and the activity of the eliminated molecule was predicted by using the model developed by the remaining molecules. The predictive power of the selected model was also confirmed by external cross validation of test set compounds which is denoted by $\mathrm{R}^{2}$ pred.

\section{Results and Discussion}

The structural details of the compounds used in the present study along with $\log 1 / \mathrm{C}$ values of compounds have been presented in Table 1. Correlation matrix showing relatedness among parameters and activity is presented in Table 2. A close look at this table reveals that the dipole $\mathrm{Y}$ is the only parameter which is suitable for modeling the anti-fungal activity. Thecalculated parameters also contain three indicator parameters $\mathrm{IP}_{1}, \mathrm{IP}_{2}$, and $\mathrm{IP}_{3}$. $\mathrm{IP}_{1}$ has been given a value of 1 when $\mathrm{N}$ is present at $\mathrm{X}$ otherwise its value is assigned as zero. $\mathrm{IP}_{2}$ has been assigned a value of unity if $\mathrm{R}_{1}$ contains $-\mathrm{NO}_{2}$, otherwise its value is zero and similarly $\mathrm{IP}_{3}$ has given a value of 1 if $\mathrm{Z}$ contains $-\mathrm{CH}_{2}$ otherwise its value is zero. The correlation matrix indicated good correlation of antifungal activity with indicator parameter $\mathrm{IP}_{2}$. However, this correlation has a lower magnitude than the previous one. The data was subjected to regression analysis and statistically significant correlations obtained have been reported in Table 3 .

One variable model (model 6, Table 3)

$\log 1 / \mathrm{C}=0.0923( \pm 0.0088) \mathrm{D} . \mathrm{Y}+4.0999$

$\mathrm{N}=55, \mathrm{R}^{2}=0.6744, \mathrm{R}_{\mathrm{A}}^{2}=0.6683, \mathrm{Se}=0.0308, \mathrm{~F}=109.779, \mathrm{Q}=26.6629$

The best one parametric model contains Dipole $\mathrm{Y}$ for which the $\mathrm{R}^{2}$ value comes to be0.6744.

Two variable model (model 10, Table 3)

$\log 1 / \mathrm{C}=0.0866( \pm 0.0078) \mathrm{D} . \mathrm{Y}+0.1197( \pm 0.0282) \mathrm{Y}$ length +3.2002

$\mathrm{N}=55, \mathrm{R}^{2}=0.7580, \mathrm{R}_{\mathrm{A}}^{2}=0.7487, \mathrm{Se}=0.0268, \mathrm{~F}=81.438, \mathrm{Q}=32.4863$

The systematic addition of $Y$ length and indicator parameters gave five bi-parametric correlations which were found to be statistically better than the mono parametric correlations. However the best bi parametric model contains dipole $\mathrm{Y}$ and $\mathrm{Y}$ length. The $\mathrm{R}^{2}$ for this model comes out to be 0.7580 . The adjusted $\mathrm{R}^{2}$ for this model is 0.7487 which clearly indicates that addition of $Y$ length is justified.

Three variable model (model 15, Table 3 )

$\log 1 / \mathrm{C}=0.0590( \pm 0.0085)$ D. $\mathrm{Y}+0.1946( \pm 0.0408) \mathrm{IP}_{2}+$

$0.1703( \pm 0.0335) \mathrm{IP}_{3}+4.0516$

$\mathrm{N}=55, \mathrm{R}^{2}=0.8242, \mathrm{R}_{\mathrm{A}}^{2}=0.8138, \mathrm{Se}=0.0231, \mathrm{~F}=79.691, \mathrm{Q}=39.3011$

Four variable model (model 19, Table 3)

$\log 1 / \mathrm{C}=0.0462( \pm 0.0078) \mathrm{D} . \mathrm{Y}+0.1532( \pm 0.0346) \mathrm{IP}_{1}+$

$0.2556( \pm 0.0376) \mathrm{IP}_{2}+0.1974( \pm 0.0293) \mathrm{IP}_{3}+4.0217$

$\mathrm{N}=55, \mathrm{R}^{2}=0.8736, \mathrm{R}_{\mathrm{A}}^{2}=0.8635, \mathrm{Se}=0.0197, \mathrm{~F}=86.409, \mathrm{Q}=47.4450$

Five variable model (model 21, Table 3) 
$\log 1 / \mathrm{C}=0.0483( \pm 0.0068) \mathrm{D} . \mathrm{Y}+0.1960( \pm 0.0318) \mathrm{IP}_{1}+0.2146( \pm 0.0341) \mathrm{IP}_{2}+$

$0.1508( \pm 0.0278) \mathrm{IP}_{3}+0.0935( \pm 0.0225) \mathrm{Y}$ length +3.3253

$\mathrm{N}=55, \mathrm{R}^{2}=0.9065, \mathrm{R}_{\mathrm{A}}^{2}=0.8970, \mathrm{Se}=0.0172, \mathrm{~F}=95.030, \mathrm{Q}=55.3548$

Six variable model (model 22, Table 3 )

$\log 1 / \mathrm{C}=-0.0254( \pm 0.0054)$ D. mag $+0.0449( \pm 0.0057) \mathrm{D} . \mathrm{Y}+0.2289( \pm 0.0276) \mathrm{IP}_{1}+0.2869( \pm 0.0325)$ $\mathrm{IP}_{2}+0.1553( \pm 0.0233) \mathrm{IP}_{3}+$

$0.1249( \pm 0.0200) \mathrm{Y}$ length +3.1396

$\mathrm{N}=55, \mathrm{R}^{2}=0.9358, \mathrm{R}_{\mathrm{A}}^{2}=0.9278, \mathrm{Se}=0.0144, \mathrm{~F}=116.576, \mathrm{Q}=67.1783$

Further improvement in $\mathrm{R}^{2}$ and adjusted $\mathrm{R}^{2}$ is observed in the three, four, five and six parametric models. The $\mathrm{R}^{2}$ and adj. $\mathrm{R}^{2}$ values for the six parametric model containing dipole mag., dipole $\mathrm{Y}, \mathrm{Y}$ length, $\mathrm{IP}_{1}, \mathrm{IP}_{2}$, and $\mathrm{IP}_{3}$ have come out to be 0.9358 and 0.9278 respectively and the $\mathrm{Q}$ value [10-11] has come out to be 67.18 . From these values we can infer that the six parametric model is the best for modeling the present set of compounds.

The observed activity has been plotted against estimated activity and such comparison is demonstrated in Figure 1. The predictive power of the model has come out to be 0.9359 suggesting that the model can explain $94 \%$ of the activity values. Further confirmation is obtained by estimating the $\log 1 / \mathrm{C}$ values of present set of compounds using model22 (Table 4). The predicted $\log 1 / \mathrm{C}$ values are in good agreement with observed values showing that the proposed model is best suited for estimating log $1 / \mathrm{C}$ values of present set of compounds. On the basis of cross validated parameters (Table 5) the six parametric model discussed above is found to the best model for which the cross validated $\mathrm{R}^{2}$ value comes out to be 0.9314 (Table 5).

Lowest value of PSE, SPRESS and PRESS/ SSY further confirmed our findings. .The ratio PRESS/SSY can be used to calculate approximate confidence intervals of prediction of new compounds. To be a reasonable and significant QSAR model the ratio PRES/SSY should be less than $0.4(\mathrm{PRESS} / \mathrm{SSY}<0.4)$ and the value of this ratio smaller than 0.1 indicates an excellent model. From Table 5 it is clear that the six parametric model (model no.22, eqn. 6) have the PRESS/SSY less than 0.1 indicating that this model have best predicting capacity. $\mathrm{R}_{\mathrm{CV}}^{2}$ is the cross validated squared correlation coefficient. The highest $\mathrm{R}_{\mathrm{CV}}^{2}$ value for model 22 (eqn. 6) further confirms our predictions. The two important cross-validation parameters Uncertainty in prediction

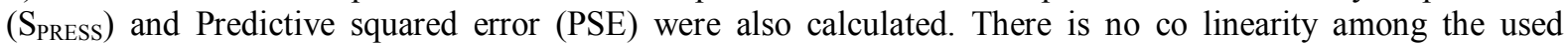
parameters which has been established by ridge analysis as well as variance inflation factor calculated from the model (Table 6, Fig. 2 \& Fig. 3). . The parameters whose VIF value is greater than 10 will show co linearity. A perusal of this table shows that in all the cases VIF are less than 10 which mean that all the proposed models reported by us are free from co linearity. Similarly if $\lambda$ (Eigen value)is found to be greater than 5 then the model will suffer from co linearity. The Table 6 shows that for all the parameters $\lambda$ is less than 5 . Therefore, from this point of view also proposed models are free from the defect of co linearity. Another test for co linearity is condition number ( $\mathrm{k}$ ) if its value is found to be $>100$ then the co linearity exists but the values reported in Table 6 indicates that the values are $<100$. Tolerance value $(T)$ equal tolor less indicates absence of co linearity. Table 6 indicates that all the above mentioned parameters or models discussed in the study are free from multi co linearity.

External cross-validation of $\log 1 / \mathrm{C}$ value of test set is done to validate the best model obtained from training set. The results are reported in Table 5.It is clearly visible from the table that estimated activities are in good agreement with the observed activities. Therefore model 22 can be used for modeling the log $1 / \mathrm{C}$ activity of the present set of compounds. The correlation potential for the test set is 0.934 which is reported in Figure 1.

\section{Conclusions}

On the basis of above discussion following conclusions can be drawn.

1. Dipole $\mathrm{Y}$ is a parameter which can model the anti-fungal activity of present set compounds along with indicator parameters, $\mathrm{Y}$ length and dipole mag..

2. Coefficient for Dipole $\mathrm{Y}$ and $\mathrm{Y}$ length is positive suggesting that a higher value of dipole $\mathrm{Y}$ and $\mathrm{Y}$ length will favour the $\log 1 / \mathrm{C}$ activity.

3. Negative coefficient of dipole mag suggests that it has retarding effect towards the $\log 1 / \mathrm{C}$ values, hence in future designing of potent compounds their lower values will give better results.

4. Since all the indicator parameters have positive coefficients presence of $\mathrm{N}$ at $\mathrm{X}$, presence of $-\mathrm{NO}_{2}$ at $\mathrm{R}_{1}$ and presence of $-\mathrm{CH}_{2}$ at $\mathrm{Z}$ is essential for exhibition of anti-fungal activity of the present set of compounds

Therefore, while designing new antifungal agents of this series they should be retained.

\section{Acknowledgement}

One of the authors (Anita K.) is very thankful to University Grant Commission New Delhi for providing financial support (F.No.Ms-132/102003/11-12 CRO). 


\section{References}

[1]. K.G. Yu, C.H. Li, Zhou,J.L. Diao, (2009),Study on the synthesis and antimicrobial activity of novel cationic porphyrins Chin.Chem. Lett.20,411-414.

[2]. I.R. Ezabadi,C. Camoutsis,P. Zoumpoulakis,A. Geronikaki,M. Socovic,J. Clamocilija,A. Ciric,(2008), Sulfonamide-1,2,4-triazole derivatives as antifungal and antibacterial agents.Synthesis, Biological evaluation, Lipophilicity and Conformational Studies,Bioorg.Med.Che. 16, 1150-1161.

[3]. http://www.emedicine.com/emerg/byname/candidiasis.htm.

[4]. C. Hanch,T.J. Fujita,(1964), A method for the correlation of biological activity and chemical Structure,Am.Chem.Soc. 86, 16161626.

[5]. V.K.Agrawal,K.Mishra,R.Sharma,P.V.Khadikar, (2004), Topological estimation of cytotoxic activity of some anti- HIV Agents: HEPT Analogues, J. Chem. Sci., 116 (2),93.

[6]. Oleg, A.Costescu, M.V.Diudea, B.Parv, (2006), QSAR modeling of antifungal activity of some heterocyclic compounds, CROATICA CHEMICA ACTA, 79, (3), 483, 17-20.

[7]. X.Y.Yao,J.P.Panaye,J.P.Doucet,R.S.Zang, H.F.Chen, N.C.Liu,Hu Z.D., B.T.Fan, (2004), Comparative study of QSAR/QSPR correlations using support vector machines, radial basis function neural networks and multiple linear regression, J. Chem. Inf. Comput. Sci.,44,1257.

[8]. NCSS, Kaysville Utah, www.ncss.com

[9]. S.Chaterjee,A.S.Hadi, B Price, (2000), Regression Analysis by Examples, 3rd Ed. Wiley: New York.

[10]. L.Pogliani, (1994),Structure property relationships of amino acids and some dipeptides, Amino Acids, 6, $141-153$.

[11]. L.Pogliani,(1996), Modeling with Special Descriptors Derived from a Medium-Sized Set of Connectivity Indices, J. Phys. Chem., 100, 18065-18077.

Table 1. The structural details of compounds used in the present study and their experimental $\log 1 / \mathrm{C}$ values

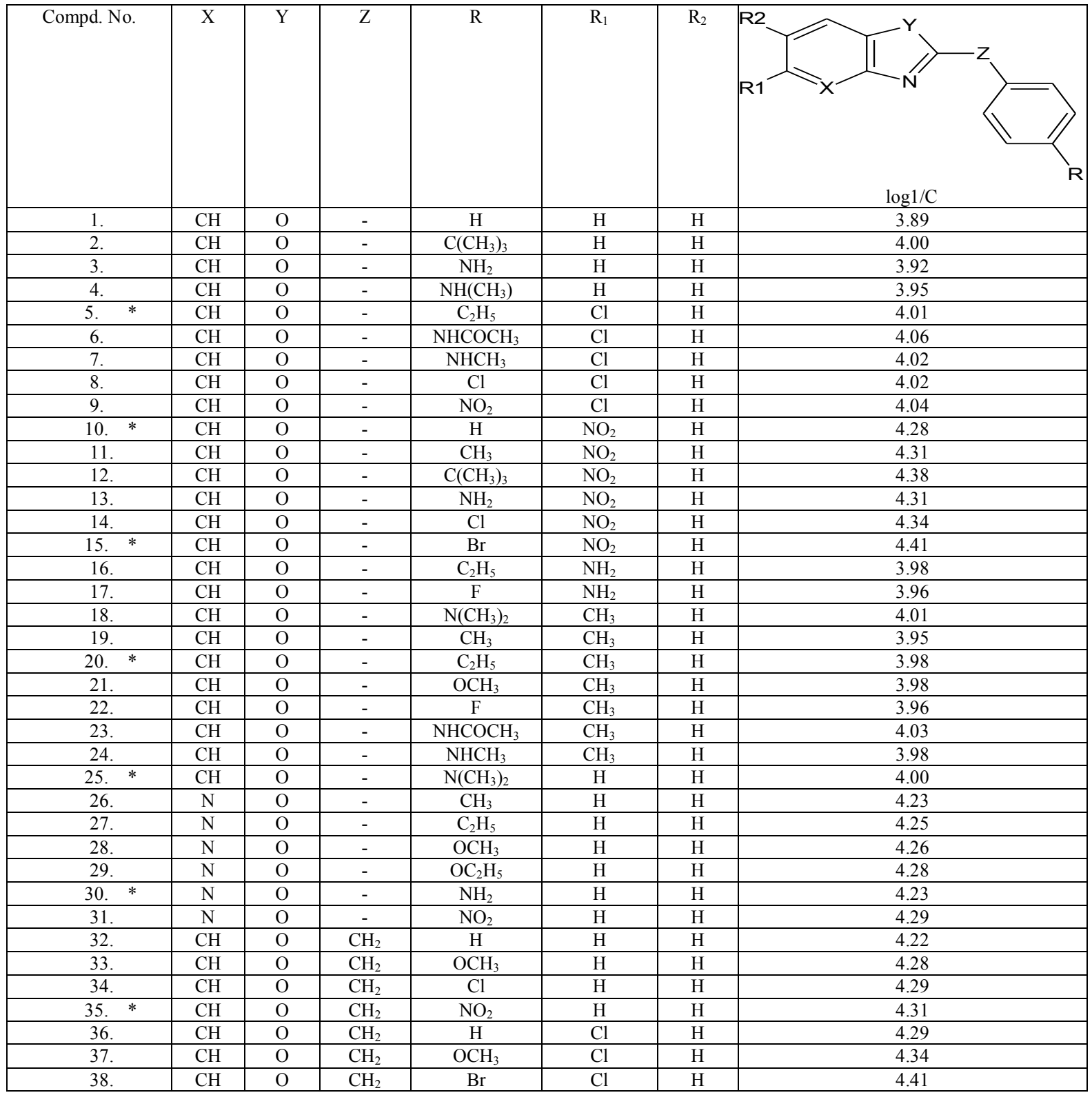


Effect of 3D parameters on Antifungal Activities of Some Heterocyclic Compounds

\begin{tabular}{|c|c|c|c|c|c|c|c|}
\hline 39. & $\mathrm{CH}$ & $\mathrm{O}$ & $\mathrm{CH}_{2}$ & $\mathrm{NO}_{2}$ & $\mathrm{Cl}$ & $\mathrm{H}$ & 4.36 \\
\hline $40 . *$ & $\mathrm{CH}$ & $\mathrm{O}$ & $\mathrm{CH}_{2}$ & $\mathrm{H}$ & $\mathrm{NO}_{2}$ & $\mathrm{H}$ & 4.61 \\
\hline 41. & $\mathrm{CH}$ & $\mathrm{O}$ & $\mathrm{CH}_{2}$ & $\mathrm{OCH}_{3}$ & $\mathrm{NO}_{2}$ & $\mathrm{H}$ & 4.66 \\
\hline 42. & $\mathrm{CH}$ & $\mathrm{O}$ & $\mathrm{CH}_{2}$ & $\mathrm{Br}$ & $\mathrm{NO}_{2}$ & $\mathrm{H}$ & 4.73 \\
\hline 43. & $\mathrm{CH}$ & $\mathrm{O}$ & $\mathrm{CH}_{2}$ & $\mathrm{Cl}$ & $\mathrm{NO}_{2}$ & $\mathrm{H}$ & 4.66 \\
\hline 44. & $\mathrm{CH}$ & $\mathrm{O}$ & $\mathrm{CH}_{2}$ & $\mathrm{NO}_{2}$ & $\mathrm{NO}_{2}$ & $\mathrm{H}$ & 4.68 \\
\hline $45 . *$ & $\mathrm{CH}$ & $\mathrm{O}$ & $\mathrm{CH}_{2} \mathrm{O}$ & $\mathrm{H}$ & $\mathrm{CH}_{3}$ & $\mathrm{H}$ & 3.98 \\
\hline 46. & $\mathrm{CH}$ & $\mathrm{O}$ & $\mathrm{CH}_{2} \mathrm{O}$ & $\mathrm{H}$ & $\mathrm{H}$ & $\mathrm{NO}_{2}$ & 3.73 \\
\hline 47. & $\mathrm{CH}$ & $\mathrm{O}$ & $\mathrm{CH}_{2} \mathrm{O}$ & $\mathrm{H}$ & $\mathrm{Cl}$ & $\mathrm{NO}_{2}$ & 3.79 \\
\hline 48. & $\mathrm{CH}$ & $\mathrm{O}$ & $\mathrm{CH}_{2} \mathrm{O}$ & $\mathrm{Cl}$ & $\mathrm{Cl}$ & $\mathrm{NO}_{2}$ & 3.83 \\
\hline 49. & $\mathrm{CH}$ & $\mathrm{O}$ & $\mathrm{CH}_{2} \mathrm{~S}$ & $\mathrm{H}$ & $\mathrm{NO}_{2}$ & $\mathrm{H}$ & 4.36 \\
\hline $50 . *$ & $\mathrm{CH}$ & $\mathrm{O}$ & $\mathrm{CH}_{2} \mathrm{~S}$ & $\mathrm{H}$ & $\mathrm{CH}_{3}$ & $\mathrm{H}$ & 4.01 \\
\hline 51. & $\mathrm{~N}$ & $\mathrm{O}$ & $\mathrm{CH}_{2} \mathrm{O}$ & $\mathrm{H}$ & $\mathrm{H}$ & $\mathrm{H}$ & 4.26 \\
\hline 52. & $\mathrm{~N}$ & $\mathrm{O}$ & $\mathrm{CH}_{2} \mathrm{O}$ & $\mathrm{Cl}$ & $\mathrm{H}$ & $\mathrm{H}$ & 4.32 \\
\hline 53. & $\mathrm{CH}$ & $\mathrm{NH}$ & $\mathrm{CH}_{2} \mathrm{O}$ & $\mathrm{Cl}$ & $\mathrm{CH}_{3}$ & $\mathrm{H}$ & 4.04 \\
\hline 54. & $\mathrm{CH}$ & $\mathrm{NH}$ & $\mathrm{CH}_{2} \mathrm{~S}$ & $\mathrm{H}$ & $\mathrm{NO}_{2}$ & $\mathrm{H}$ & 4.36 \\
\hline $55 . *$ & $\mathrm{CH}$ & $\mathrm{NH}$ & $\mathrm{CH}_{2} \mathrm{~S}$ & $\mathrm{H}$ & $\mathrm{CH}_{3}$ & $\mathrm{H}$ & 4.01 \\
\hline 56. & $\mathrm{CH}$ & $\mathrm{O}$ & $\mathrm{CH}_{2} \mathrm{O}$ & $\mathrm{H}$ & $\mathrm{COOCH}_{3}$ & $\mathrm{H}$ & 4.05 \\
\hline 57. & $\mathrm{CH}$ & $\mathrm{O}$ & $\mathrm{CH}_{2} \mathrm{O}$ & $\mathrm{Cl}$ & $\mathrm{COOCH}_{3}$ & $\mathrm{H}$ & 4.10 \\
\hline 58. & $\mathrm{CH}$ & $\mathrm{NH}$ & $\mathrm{CH}_{2} \mathrm{O}$ & $\mathrm{Cl}$ & $\mathrm{COOCH}_{3}$ & $\mathrm{H}$ & 4.10 \\
\hline 59. & $\mathrm{CH}$ & $\mathrm{NH}$ & $\mathrm{CH}_{2} \mathrm{~S}$ & $\mathrm{H}$ & $\mathrm{COOCH}_{3}$ & $\mathrm{H}$ & 4.08 \\
\hline $60 . *$ & $\mathrm{CH}$ & $\mathrm{O}$ & $\mathrm{C}_{2} \mathrm{H}_{4}$ & $\mathrm{H}$ & $\mathrm{NO}_{2}$ & $\mathrm{H}$ & 4.33 \\
\hline 61. & $\mathrm{~N}$ & $\mathrm{O}$ & $\mathrm{C}_{2} \mathrm{H}_{4}$ & $\mathrm{H}$ & $\mathrm{H}$ & $\mathrm{H}$ & 4.25 \\
\hline 62. & $\mathrm{CH}$ & $\mathrm{O}$ & - & $\mathrm{Br}$ & $\mathrm{NH}_{2}$ & $\mathrm{H}$ & 4.11 \\
\hline 63. & $\mathrm{CH}$ & $\mathrm{O}$ & $\mathrm{CH}_{2}$ & $\mathrm{Br}$ & $\mathrm{H}$ & $\mathrm{H}$ & 4.36 \\
\hline 64. & $\mathrm{CH}$ & $\mathrm{O}$ & $\mathrm{CH}_{2} \mathrm{O}$ & $\mathrm{Cl}$ & $\mathrm{H}$ & $\mathrm{H}$ & 4.02 \\
\hline $65 . *$ & $\mathrm{CH}$ & $\mathrm{NH}$ & $\mathrm{CH}_{2} \mathrm{O}$ & $\mathrm{H}$ & $\mathrm{NO}_{2}$ & $\mathrm{H}$ & 4.28 \\
\hline 66. & $\mathrm{CH}$ & $\mathrm{NH}$ & $\mathrm{CH}_{2} \mathrm{O}$ & $\mathrm{Cl}$ & $\mathrm{H}$ & $\mathrm{H}$ & 4.02 \\
\hline 67. & $\mathrm{CH}$ & $\mathrm{NH}$ & $\mathrm{CH}_{2} \mathrm{~S}$ & $\mathrm{H}$ & $\mathrm{Cl}$ & $\mathrm{H}$ & 4.04 \\
\hline 68. & $\mathrm{CH}$ & $\mathrm{NH}$ & $\mathrm{C}_{2} \mathrm{H}_{4}$ & $\mathrm{H}$ & $\mathrm{H}$ & $\mathrm{H}$ & 4.08 \\
\hline
\end{tabular}

\section{*Test Set}

Table 2. Correlation matrix

\begin{tabular}{|l|c|c|c|c|c|c|c|c|c|c|c|}
\hline & $\log 1 / \mathrm{C}$ & LUMO & D.mag & D.Y & FNSA3 & PMI.X & Y length & YZ & IP1 & IP2 & IP3 \\
\hline $\log 1 / \mathrm{C}$ & 1.00 & & & & & & & & & & \\
\hline LUMO & -0.49 & 1.00 & & & & & & & & & \\
\hline D.mag & 0.43 & -0.88 & 1.00 & & & & & & & & \\
\hline D.Y & 0.78 & -0.31 & 0.37 & 1.00 & & & & & & & \\
\hline FNSA3 & -0.51 & 0.95 & -0.90 & -0.41 & 1.00 & & & & & & \\
\hline PMI.X & 0.48 & -0.49 & 0.51 & 0.42 & -0.50 & 1.00 & & & & & \\
\hline Ylength & 0.26 & -0.43 & 0.45 & 0.22 & -0.45 & 0.83 & 1.00 & & & & \\
\hline YZ & 0.02 & -0.06 & 0.04 & 0.17 & 0.00 & 0.35 & 0.15 & 1.00 & & & \\
\hline IP1 & 0.18 & -0.02 & -0.06 & 0.12 & 0.09 & -0.28 & -0.42 & -0.40 & 1.00 & & \\
\hline IP2 & 0.65 & -0.66 & 0.61 & 0.58 & -0.72 & 0.35 & 0.32 & 0.17 & -0.21 & 1.00 & \\
\hline IP3 & 0.47 & -0.14 & 0.16 & 0.34 & -0.09 & 0.44 & 0.31 & 0.09 & 0.12 & -0.01 & 1.00 \\
\hline
\end{tabular}

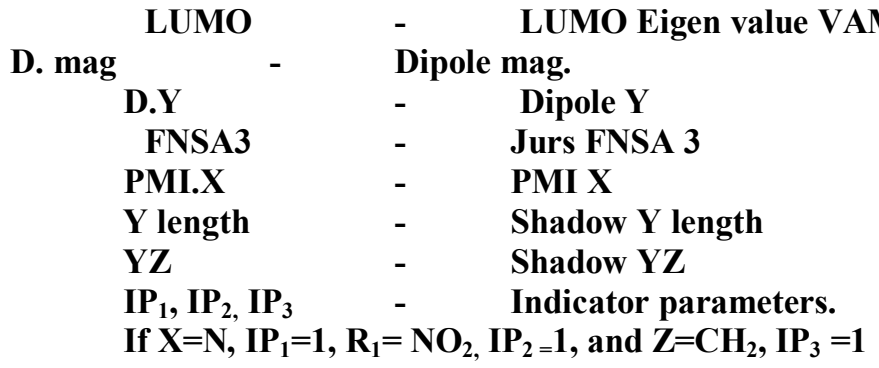


Table 3. Regression parameters and quality of correlation of training set

\begin{tabular}{|c|c|c|c|c|c|c|}
\hline $\begin{array}{l}\text { Model } \\
\text { No. }\end{array}$ & $\begin{array}{c}\text { Parameters } \\
\text { Used }\end{array}$ & $\mathrm{Se}$ & $\mathrm{R}^{2}$ & $\mathrm{R}_{\mathrm{A}}^{2}$ & F-ratio & $\mathrm{Q}=\mathrm{R} / \mathrm{Se}$ \\
\hline 1 & $\mathrm{IP}_{1}$ & 0.0530 & 0.0347 & 0.0165 & 1.906 & 3.5147 \\
\hline 2 & D. mag & 0.0507 & 0.1197 & 0.0990 & 6.936 & 6.8240 \\
\hline 3 & Y length & 0.0488 & 0.1818 & 0.1662 & 11.766 & 8.7373 \\
\hline 4 & $\mathrm{IP}_{3}$ & 0.0459 & 0.2758 & 0.2621 & 20.185 & 11.4415 \\
\hline 5 & $\mathrm{IP}_{2}$ & 0.0404 & 0.4403 & 0.4297 & 41.686 & 16.4245 \\
\hline 6 & D.Y & 0.0308 & 0.6744 & 0.6683 & 109.779 & 26.6629 \\
\hline 7 & $\begin{array}{l}\text { D. mag } \\
\text { D.Y }\end{array}$ & 0.0305 & 0.6865 & 0.6744 & 56.930 & 27.1657 \\
\hline 8 & $\begin{array}{c}\text { D.Y } \\
\mathrm{IP}_{2}\end{array}$ & 0.0280 & 0.7351 & 0.7249 & 72.149 & 30.6207 \\
\hline 9 & $\begin{array}{c}\text { D.Y } \\
\mathrm{IP}_{3}\end{array}$ & 0.0275 & 0.7458 & 0.7360 & 76.270 & 31.4035 \\
\hline 10 & $\begin{array}{c}\text { D.Y } \\
\text { Y length }\end{array}$ & 0.0268 & 0.7580 & 0.7487 & 81.438 & 32.4863 \\
\hline 11 & $\begin{array}{c}\text { D.Y } \\
\text { IP }_{2} \\
\text { Y length }\end{array}$ & 0.0255 & 0.7842 & 0.7715 & 61.783 & 34.7275 \\
\hline 12 & $\begin{array}{l}\mathrm{IP}_{1} \\
\mathrm{IP}_{2} \\
\mathrm{IP}_{3}\end{array}$ & 0.0255 & 0.7851 & 0.7724 & 62.093 & 34.7474 \\
\hline 13 & $\begin{array}{c}\text { D.Y } \\
\text { IP }_{3} \\
\text { Y length }\end{array}$ & 0.0254 & 0.7870 & 0.7745 & 62.816 & 34.9264 \\
\hline 14 & $\begin{array}{c}\text { D.Y } \\
\text { IP }_{1} \\
\text { Y length }\end{array}$ & 0.0244 & 0.8031 & 0.7915 & 69.349 & 36.7278 \\
\hline 15 & $\begin{array}{l}\text { D.Y } \\
\text { IP2 } \\
\text { IP3 }\end{array}$ & 0.0231 & 0.8242 & 0.8138 & 79.691 & 39.3011 \\
\hline 16 & $\begin{array}{c}\text { D.Y } \\
\mathrm{IP}_{1} \\
\mathrm{IP}_{3} \\
\text { Y length }\end{array}$ & 0.0228 & 0.8309 & 0.8174 & 61.430 & 39.9797 \\
\hline 17 & $\begin{array}{c}\text { D.Y } \\
\mathrm{IP}_{2} \\
\mathrm{IP}_{3} \\
\mathrm{Y} \text { length }\end{array}$ & 0.0226 & 0.8341 & 0.8208 & 62.846 & 40.4111 \\
\hline 18 & $\begin{array}{c}\text { D.Y } \\
\mathrm{IP}_{1} \\
\mathrm{IP}_{2} \\
\text { Y length }\end{array}$ & 0.0215 & 0.8505 & 0.8386 & 71.121 & 42.8942 \\
\hline 19 & $\begin{array}{c}\text { D.Y } \\
\mathrm{IP}_{1} \\
\mathrm{IP}_{2} \\
\mathrm{IP}_{3}\end{array}$ & 0.0197 & 0.8736 & 0.8635 & 86.409 & 47.4450 \\
\hline 20 & $\begin{array}{c}\text { D. mag } \\
\text { D.Y } \\
\mathrm{IP}_{1} \\
\mathrm{IP}_{2} \\
\mathrm{IP}_{3}\end{array}$ & 0.0191 & 0.8837 & 0.8718 & 74.459 & 49.2174 \\
\hline 21 & $\begin{array}{c}\text { D.Y } \\
\mathrm{IP}_{1} \\
\mathrm{IP}_{2} \\
\mathrm{IP}_{3} \\
\text { Y length }\end{array}$ & 0.0172 & 0.9065 & 0.8970 & 95.030 & 55.3548 \\
\hline 22 & $\begin{array}{c}\text { D. mag } \\
\text { D.Y } \\
\mathrm{IP}_{1} \\
\mathrm{IP}_{2} \\
\mathrm{IP}_{3} \\
\text { Y length }\end{array}$ & 0.0144 & 0.9358 & 0.9278 & 116.576 & 67.1783 \\
\hline
\end{tabular}


Effect of 3D parameters on Antifungal Activities of Some Heterocyclic Compounds

Table 4. Observed and estimated values of $\log 1 / \mathrm{C}$ of Training and Test setusing model no. 22(Table 3)

\begin{tabular}{|c|c|c|c|}
\hline Compd. No & $\begin{array}{c}\text { Observed } \\
\log 1 / C\end{array}$ & $\begin{array}{c}\text { Estimated } \\
\log 1 / C\end{array}$ & Residual \\
\hline 1 & 3.89 & 4.01 & -0.12 \\
\hline 2 & 4.00 & 4.01 & -0.01 \\
\hline 3 & 3.92 & 4.00 & -0.07 \\
\hline 4 & 3.95 & 4.01 & -0.06 \\
\hline $5^{*}$ & 4.01 & 4.06 & -0.05 \\
\hline 6 & 4.06 & 4.03 & 0.03 \\
\hline 7 & 4.02 & 4.02 & -0.01 \\
\hline 8 & 4.02 & 4.03 & 0.00 \\
\hline 9 & 4.04 & 3.91 & 0.13 \\
\hline $10 *$ & 4.28 & 4.34 & -0.06 \\
\hline 11 & 4.31 & 4.32 & -0.01 \\
\hline 12 & 4.38 & 4.36 & 0.02 \\
\hline 13 & 4.31 & 4.34 & -0.03 \\
\hline 14 & 4.34 & 4.35 & -0.01 \\
\hline $15^{*}$ & 4.41 & 4.35 & 0.05 \\
\hline 16 & 3.98 & 3.99 & -0.01 \\
\hline 17 & 3.96 & 3.97 & -0.01 \\
\hline 18 & 4.01 & 3.99 & 0.01 \\
\hline 19 & 3.95 & 4.01 & -0.06 \\
\hline $20 *$ & 3.98 & 3.99 & -0.01 \\
\hline 21 & 3.98 & 3.97 & 0.02 \\
\hline 22 & 3.96 & 3.95 & 0.01 \\
\hline 23 & 4.03 & 3.95 & 0.08 \\
\hline 24 & 3.98 & 4.03 & -0.06 \\
\hline $25 *$ & 4.00 & 4.00 & 0.01 \\
\hline 26 & 4.23 & 4.24 & -0.01 \\
\hline 27 & 4.25 & 4.29 & -0.04 \\
\hline 28 & 4.26 & 4.26 & 0.00 \\
\hline 29 & 4.28 & 4.35 & -0.06 \\
\hline $30 *$ & 4.23 & 4.23 & 0.00 \\
\hline 31 & 4.29 & 4.31 & -0.03 \\
\hline 32 & 4.22 & 4.19 & 0.03 \\
\hline 33 & 4.28 & 4.18 & 0.11 \\
\hline 34 & 4.29 & 4.31 & -0.02 \\
\hline $35 *$ & 4.31 & 4.37 & -0.06 \\
\hline 36 & 4.29 & 4.35 & -0.06 \\
\hline 37 & 4.34 & 4.28 & 0.06 \\
\hline 38 & 4.41 & 4.39 & 0.02 \\
\hline 39 & 4.36 & 4.42 & -0.06 \\
\hline $40 *$ & 4.61 & 4.69 & -0.08 \\
\hline 41 & 4.66 & 4.64 & 0.01 \\
\hline 42 & 4.73 & 4.73 & -0.01 \\
\hline 43 & 4.66 & 4.67 & -0.01 \\
\hline 44 & 4.68 & 4.64 & 0.04 \\
\hline $45 *$ & 3.98 & 4.14 & -0.16 \\
\hline 46 & 3.73 & 3.81 & -0.08 \\
\hline 47 & 3.79 & 3.83 & -0.05 \\
\hline 48 & 3.83 & 3.85 & -0.02 \\
\hline 49 & 4.36 & 4.34 & 0.02 \\
\hline $50 *$ & 4.01 & 4.01 & 0.00 \\
\hline 51 & 4.26 & 4.26 & 0.00 \\
\hline 52 & 4.32 & 4.22 & 0.10 \\
\hline 53 & 4.04 & 4.02 & 0.02 \\
\hline 54 & 4.36 & 4.38 & -0.02 \\
\hline $55 *$ & 4.01 & 4.09 & -0.08 \\
\hline 56 & 4.05 & 4.02 & 0.03 \\
\hline 57 & 4.10 & 3.99 & 0.11 \\
\hline 58 & 4.10 & 4.07 & 0.03 \\
\hline 59 & 4.08 & 4.13 & -0.06 \\
\hline $60 *$ & 4.33 & 4.38 & -0.08 \\
\hline 61 & 4.25 & 4.20 & 0.05 \\
\hline 62 & 4.11 & 4.15 & -0.04 \\
\hline
\end{tabular}




\begin{tabular}{|c|c|c|c|}
\hline 63 & 4.36 & 4.19 & 0.17 \\
\hline 64 & 4.02 & 3.94 & 0.08 \\
\hline $65^{*}$ & 4.28 & 4.35 & -0.06 \\
\hline 66 & 4.02 & 4.08 & -0.06 \\
\hline 67 & 4.04 & 4.11 & -0.07 \\
\hline 68 & 4.08 & 4.08 & 0.00 \\
\hline
\end{tabular}

Table 5. Cross validation parameters of proposed models (Table 3 )

\begin{tabular}{|c|c|c|c|c|c|}
\hline $\begin{array}{l}\text { Model } \\
\text { No. }\end{array}$ & Parameters used & PRESS/SSY & $\mathrm{R}_{\mathrm{CV}}^{2}$ & $S_{\text {PRESS }}$ & PSE \\
\hline 6 & D.Y & 0.4828 & 0.5172 & 0.1283 & 0.1259 \\
\hline 10 & D.Y,Y length & 0.3192 & 0.6808 & 0.1116 & 0.1085 \\
\hline 15 & D.Y, IP2, IP3 & 0.2133 & 0.7867 & 0.0961 & 0.0925 \\
\hline 19 & D.Y, IP1IP ${ }_{2}, \mathrm{IP}_{3}$ & 0.1447 & 0.8553 & 0.0823 & 0.0784 \\
\hline 21 & $\begin{array}{l}\text { D.Y, } \mathrm{IP}_{1}, \mathrm{IP}_{2}, \mathrm{IP}_{3} \\
\text { Y length }\end{array}$ & 0.1031 & 0.8969 & 0.0715 & 0.0675 \\
\hline 22 & $\begin{array}{l}\text { D.mag,D.Y, } \mathrm{IP}_{1}, \mathrm{IP}_{2}, \\
\mathrm{IP}_{3}, \mathrm{Y} \text { length }\end{array}$ & 0.0686 & 0.9314 & 0.0598 & 0.0559 \\
\hline
\end{tabular}

Table 6. Ridge analysis for the six variable model (model 22)

\begin{tabular}{|c|l|l|l|l|}
\hline Independent variable & VIF & T & $\boldsymbol{\lambda}$ & $\mathbf{k}$ \\
\hline D mag & 1.74 & 0.57 & 2.43 & 1.00 \\
D.Y & 1.95 & 0.51 & 1.29 & 1.88 \\
Y length & 1.80 & 0.55 & 0.99 & 2.33 \\
IP $_{1}$ & 1.45 & 0.69 & 0.68 & 3.56 \\
$\mathrm{IP}_{2}$ & 2.41 & 0.42 & 0.36 & 6.68 \\
$\mathrm{IP}_{3}$ & 1.43 & 0.70 & 0.22 & 10.64 \\
& & & & \\
\hline
\end{tabular}

VIF $=$ Variance inflation factor

$\lambda=$ Eigen Values

$\mathbf{T}=$ Tolerance

$\mathbf{k}=$ Condition number

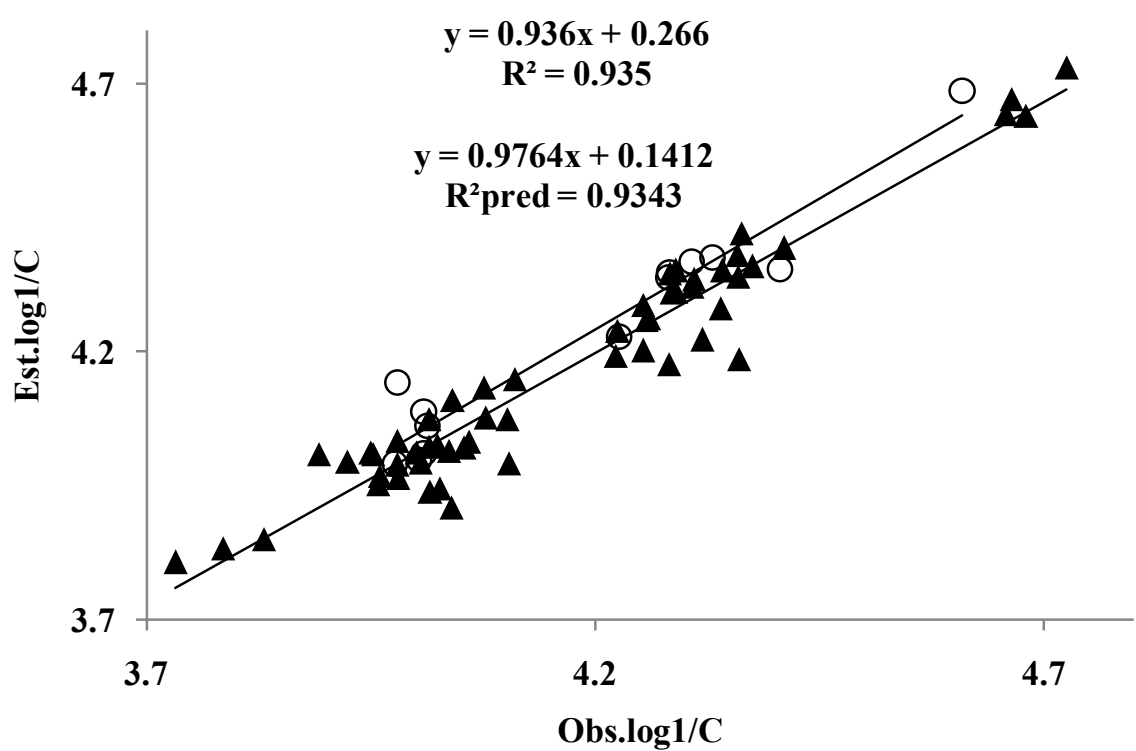

Fig. 1. Correlation between observed and estimated $\log 1 / \mathrm{C}$ values using model 22 


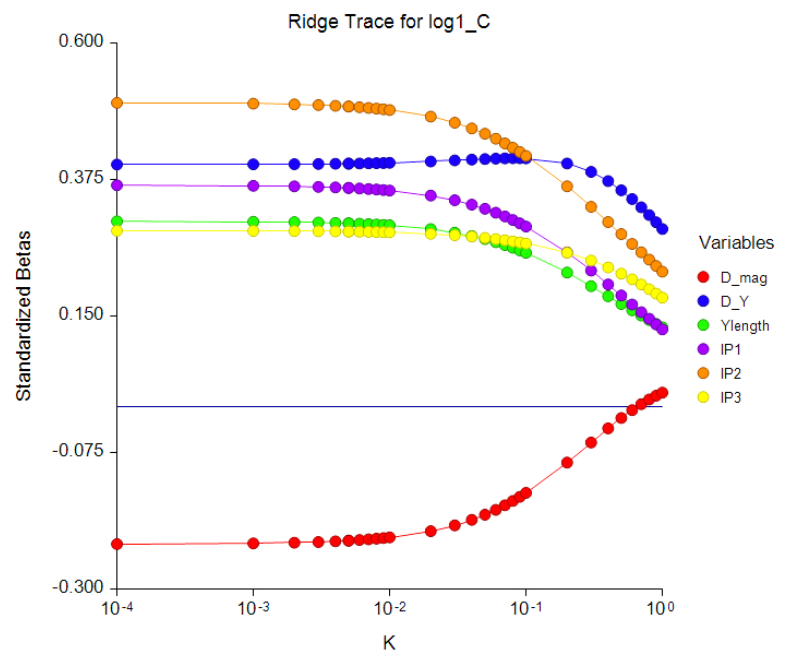

Fig. 2.Ridge Trace for six variable model (model-22)

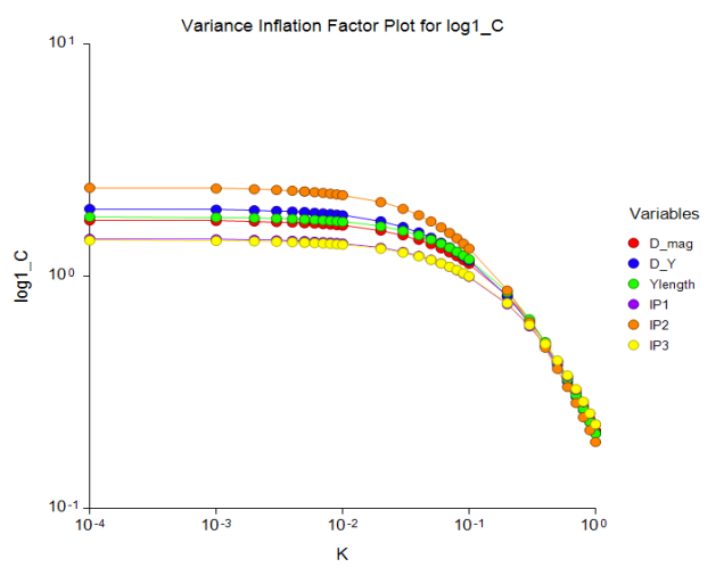

Fig.3. VIF plot for six variable model (model-22) 